\title{
Desenvolvimento de um Modelo Experimental de Endometriose em Coelha
}

\section{Development of an experimental model of endometriosis in rabbits}

Aluno: Julio César Rosa e Silva

Orientador: Prof. Dr. Antonio Alberto Nogueira

Dissertação de Mestrado apresentada a Faculdade de Medicina de Ribeirão Preto da Universidade de São Paulo Departamento de Ginecologia e Obstetrícia, em 11 de maio de 2004.

Introdução: a endometriose se caracteriza pela presença de tecido endometrial em atividade fora da cavidade uterina. Várias são as teorias que tentam explicar a sua etiopatogenia, porém nenhuma delas isoladamente é satisfatória. Em humanos, a heterogeneidade das lesões, dos sinais e sintomas associados a endometriose e os aspectos éticos dificultam o desenvolvimento de metodologias científicas para melhor compreendermos a sua etiologia e fisiopatologia, por isso, técnicas com modelos experimentais em animais têm sido desenvolvidas.

Objetivos: desenvolvimento de um modelo experimental de endometriose em coelhas, de modo que possibilite caracterizar a progressão e a evolução temporal da doença, com sua avaliação macroscópica em dois tempos diferentes: 4 e 8 semanas após o implante da lesão, utilizando-se a laparoscopia para obtenção das imagens e análise histológica posterior.

Material e Métodos: foram utilizadas 30 coelhas Nova Zelândia adultas nas quais a endometriose foi induzida por meio da fixação de um fragmento de corno uterino de 5,0 x 5,0 mm no peritônio da parede pélvica. Os animais foram submetidos à laparoscopia diagnóstica, com o objetivo de verificar a viabilidade e documentar o aspecto visual endoscópico das lesões, sendo 15 deles sacrificados após quatro semanas (Grupo I) e 15 após oito semanas (Grupo II) da indução. Os implantes foram medidos em seu maior diâmetro e reti- rados, sendo posteriormente fixados e processados para análise morfológica. Os grupos foram comparados quanto à presença de lesão visualizada à laparoscopia, seu maior diâmetro, presença de aderências e histologia da mesma.

Resultados: a presença de lesão visualizada à laparoscopia após 4 semanas foi de 100\%, sendo $64 \%$ císticas. Após 8 semanas, a porcentagem de lesões foi de $80 \%$ sendo $66 \%$ císticas. As aderências estavam presentes em $80 \%$ das coelhas após 8 semanas (sendo $13 \%$ nos implantes) e em $71 \%$ das coelhas após 4 semanas (ausentes nos implantes). O maior diâmetro das lesões após 8 semanas de implante foi maior que após 4 semanas ( $\mathrm{p}<0,0001)$. A análise histológica mostrou apenas tecido endometrial (glândula e estroma) em atividade nos 2 grupos.

Conclusão: a utilização desse modelo experimental de endometriose em coelhas mostrou ser possível reproduzir a doença nesse animal, sendo viável e de fácil execução. Permitiu documentar as características e a progressão dos implantes através da laparoscopia, verificando-se seu crescimento e desenvolvimento histopatológico, sendo observado que as lesões após oito semanas são maiores que após 4 semanas., mas com mesmo aspecto histológico.

Palavras-chave: Endometriose. Modelo experimental. Laparoscopia.

\section{Associação entre a Carǵa Viral e os Linfócitos TCD4 com as Lesões Intra-epiteliais do Colo Uterino em Mulheres Infectadas pelo Virus da Imunodeficiência Humana}

\begin{abstract}
Association between Viral Load and T CD4 Lymphocytes and Cervical Intraepithelial Lesions in Women Infected with Human Immunodeficiency Virus
\end{abstract}

Autora: Angela Cristina Labanca de Araújo

Orientador: Prof. Dr. Victor Hugo de Melo

Dissertação apresentada ao Departamento de Ginecologia e Obstetrícia da Faculdade de Medicina da Universidade Federal de Minas Gerais, Belo Horizonte, para obtenção do título de Mestre, em 19 de dezembro de 2003.

Objetivos: avaliar se a contagem de linfócitos T CD4 e a carga viral do HIV influenciam na presença ou gravidade das neoplasias intra-epiteliais cervicais.

Pacientes e Métodos: estudo transversal, retrospectivo, no qual foram selecionadas 135 pacientes HIV positi- vas, oriundas do Centro de Treinamento e Referências em Doenças Infecciosas e Parasitárias Orestes Diniz. Todas foram submetidas a biópsia do colo uterino, dosagem da carga viral do HIV e contagem de linfócitos T CD4. Foram estabelecidas para a análise dos dados 
cinco categorias para a carga viral e células CD4, que demonstram o momento da obtenção dos valores laboratoriais em relação a biópsia, e cortes nas dosagens da carga viral ( $\leq 400$ cópias /ml; de 401 a 50.000 cópias / $\mathrm{ml} ;>50.000$ cópias $/ \mathrm{ml}$ ) e contagem de linfócitos T CD4 ( $<200$ células $/ \mathrm{mm}^{3}$; de 200 a 350 células $/ \mathrm{mm}^{3} ;>350$ células $/ \mathrm{mm}^{3}$ ). Realizou-se o teste qui-quadrado, quiquadrado de tendência linear, análise de variância e regressão logística. Estabeleceu-se a significância estatística para p <0,05 e intervalo de confiança a 95\%. Resultados: não houve tendência de risco da mulher HIV positiva apresentar NIC com o aumento da carga viral ou diminuição das células CD4. Quando comparado a carga viral mais antiga com a presença ou ausência de NIC houve diferença significante $(p=0,04$; OR = 3, 1 [1,059,53]) e sensibilidade de $80 \%$ no corte de 400 cópias / ml. A regressão logística confirmou este resultado (OR $=3,2[1,09-9,44])$. Não houve qualquer associação significante entre a gravidade da NIC com a carga viral do HIV. Nenhuma associação foi encontrada na análise univariada e regressão logística para a contagem das células CD4 com a presença ou gravidade da NIC.

Conclusão: as pacientes com dosagem da carga viral do $\mathrm{HIV}$ maior que 400 cópias $/ \mathrm{ml}$ realizada até no máximo dois anos antes da biópsia do colo uterino, apresentaram risco 3,1 vezes maior de desencadear NIC. A contagem de linfócitos T CD4 não influenciou na presença ou gravidade da NIC. Também não houve influência da carga viral na gravidade das lesões cervicais.

Palavras-chave: Colo do útero: lesões pré-neoplásicas. HIV. AIDS. Carga viral. Linfócitos T.

\title{
0 Sistema Intra-uterino Liberador de Levonorgestrel Reduz os Niveis de CA-125 em Pacientes
}

\section{Portadoras de Endometriose}

\author{
Effect of Levonorgestrel-Releasing Intrauterine System on the Reduction of CA-125 Levels in Patients with \\ Endometriosis
}

Aluna: Ana Carolina Japur de Sá Rosa e Silva

Orientador: Prof. Dr. Rui Alberto Ferriani

Tese de Doutorado apresentada ao Departamento de Ginecologia e Obstetrícia da Faculdade de Medicina de Ribeirão Preto - Universidade de São Paulo, ao Programa de Ginecologia e Obstetrícia, em 25 de junho de 2004.

Introdução: as opções atuais de tratamento para algia pélvica relacionada com a endometriose disponiveis no mercado estão relacionadas a elevado custo e reações adversas que limitam o tempo de tratamento. Recentemente tem sido proposto o uso do Sistema Intrauterino de Levonorgestrel (SIU-LNG) no tratamento de pacientes com endometriose. Este estudo propõe a verificação da eficácia deste método após um seguimento de 6 meses.

Pacientes e Métodos: foram estudadas 44 pacientes com endometriose confirmada por laparoscopia e com persistência da dor após o procedimento cirúrgico, seguidas no ambulatório de dor pélvica do HC-FMRP, randomizadas em 2 grupos de tratamento: grupo SIULNG com 21 pacientes submetidas à colocação do SIULNG e grupo GnRHa 23 pacientes tratadas com acetato de leuprolide por um período de 6 meses. Os grupos eram homogêneos quanto à idade, escore de dor prévio ao tratamento e estádio da endometriose, predominando estádios III e IV (ASRM). As pacientes foram avaliadas quanto ao escore de dor, marcadores tumorais (CA-125 e CA 19-9) e marcadores de atividade inflamatória (SAA e PCR) no início do estudo e após 6 meses de seguimento. Para estatística foram utilizados os testes $\mathrm{t}$ de Student para as variáveis com distribuição normal e teste de Mann-Whitney para as variáveis sem distribuição gaussiana ou variáveis não contínuas, considerando-se significância estatística $\mathrm{p}<0,05$. Resultados: Os valores de CA-125, CA19-9, SAA e PCR foram semelhantes estatisticamente em ambos os grupos na avaliação pré-tratamento, sendo que o CA-125 mostrava-se elevado, enquanto os demais marcadores apresentavam-se normais. Houve melhora significativa no quadro álgico da paciente com redução significativa no escore de dor de 8 para 1 no grupo SIU-LNG (p $<0,0001$ ) e de 7 para 0 no grupo GnRHa (p $<0,0001)$. Também houve redução nos valores de CA-125 em ambos os grupos de tratamento, de 22,91 $\pm 21,21 \mathrm{U} / \mathrm{ml}$ para $12,07 \pm 11,34 \mathrm{U} / \mathrm{ml}$ no grupo SIU-LNG e de 30,62 $\pm 33,81 \mathrm{U} / \mathrm{ml}(\mathrm{p}=0,0369)$ para $7,49 \pm 4,85 \mathrm{U} / \mathrm{ml}$ no grupo GnRHa ( $\mathrm{p}=0,0002)$. O CA 19-9 e os marcadores inflamatórios não sofreram redução em seis meses de seguimento, em ambos os grupos.

Conclusão: após seis meses de tratamento tanto o análogo do GnRH quanto o SIU-LNG melhoram o quadro de dor causado pela endometriose e reduzem os valores séricos de CA-125, num seguimento de 6 meses.

Palavras-Chave: Endometriose. CA-125. Dor pélvica. Sistema intra-uterino liberador de levonorgestrel. Análogo do GnRH. Marcadores tumorais 